\title{
Analysis of a wound rotor induction machine low frequency vibroacoustic emissions under stator winding fault conditions
}

DOI:

10.1049/cp.2016.0335

\section{Document Version}

Accepted author manuscript

Link to publication record in Manchester Research Explorer

\section{Citation for published version (APA):}

Sarma, N., Li, S., Durovic, S., Smith, A. C., \& Rowland, S. (2016). Analysis of a wound rotor induction machine low frequency vibroacoustic emissions under stator winding fault conditions. In 8th IET International Conference on Power Electronics, Machines and Drives, PEMD; Glasgow (2016) https://doi.org/10.1049/cp.2016.0335

\section{Published in:}

8th IET International Conference on Power Electronics, Machines and Drives, PEMD; Glasgow (2016)

\section{Citing this paper}

Please note that where the full-text provided on Manchester Research Explorer is the Author Accepted Manuscript or Proof version this may differ from the final Published version. If citing, it is advised that you check and use the publisher's definitive version.

\section{General rights}

Copyright and moral rights for the publications made accessible in the Research Explorer are retained by the authors and/or other copyright owners and it is a condition of accessing publications that users recognise and abide by the legal requirements associated with these rights.

\section{Takedown policy}

If you believe that this document breaches copyright please refer to the University of Manchester's Takedown Procedures [http://man.ac.uk/04Y6Bo] or contact uml.scholarlycommunications@manchester.ac.uk providing relevant details, so we can investigate your claim.

\section{OPEN ACCESS}




\title{
Analysis of Wound Rotor Induction Machine Low Frequency Vibroacoustic Emissions under Stator Winding Fault Conditions
}

\author{
N Sarma, Q Li , S. Djurović, A C Smith, S M Rowland \\ University of Manchester, School of Electrical and Electronic Engineering, Power Division, Manchester, UK \\ Email: N.Sarma@manchester.ac.uk,qi.li@manchester.ac.uk
}

Keywords: Condition monitoring, winding fault, vibration analysis, acoustic emissions, wound rotor induction machines

\begin{abstract}
This paper examines the wide band vibroacoustic emissions of a low power industrial wound rotor induction machine (WRIM) design operating with balanced windings and with a stator winding fault. The aim of the presented study is to enable a clearer understanding of the possible spectral content of the WRIM vibration and acoustic emission signals in healthy and electrical fault conditions, with a view to assessing the possibility of vibroacoustic based electrical fault recognition. For this purpose an experimental study is undertaken on a laboratory test rig in which the low frequency spectral content of the synchronously recorded vibration and acoustic emissions signals is mapped and correlated for healthy and faulty operating conditions. It is shown that the wide band winding fault induced changes can be clearly correlated and recognised in both the vibration in the acoustic emission signals of the investigated machine design
\end{abstract}

\section{Introduction}

With the continued large scale plans for development of offshore wind generation capacity comes a pressing need for lowering the accompanying high wind turbine (WT) operation and maintenance (O\&M) costs [1]. The development and utilisation of improved diagnostic reliability condition monitoring (CM) solutions is widely seen as a means of achieving the offshore wind energy cost reduction. Effective diagnostic techniques aimed at WT drive-train component failure modes, including both the gearbox and the electric generator are of strong interest in this respect [2]. The generator faults in particular have recently been indicated as one of the major causes of WT downtime with reports of high rates of winding fault incidents in practical applications $[3,4]$.

The first step to enabling improved diagnostics is in providing means of better understanding and interpretation of the failure mode signature in the monitored signals of interest. In addition, by identifying and correlating fault indices in multiple CM signals valuable advantage can be obtained in enabling the definition of multi-signal based, high diagnostic reliability $\mathrm{CM}$ indices. The current state-of-the-art in WT drive-train commercial CM systems is predominantly focused on vibration analysis, however the inclusion of acoustic emissions (AE) monitoring of rotating components into the next generation of high fidelity $\mathrm{CM}$ platforms is starting to gain commercial interest [5].
Achieving more effective recognition of the WT generator electrical fault remains a challenge for the existing CM systems [5]. The diagnosis of electrical faults in wound rotor induction machines (WRIMs), widely used in modern MW size type-II and type-III configuration WT drives [6-9], is of particular interest in this respect. This research examines the correlation of the recently reported winding fault low frequency wide band signature in the vibration signal of an industrial WRIM design with the AE signal $[10,11]$. The underlying purpose of this study is to map the spectral nature of the WRIM AE signal and its relationship with the frame vibration signal under healthy as well as electrical fault conditions and examine the possibility of improved reliability, multi-signal based, recognition of electrical fault conditions. To this end a series of tests is undertaken on a fully instrumented WRIM laboratory system and the obtained vibration and AE signals low frequency spectral contents studied for consistent wide band spectral patterns under healthy and electrical fault conditions.

\section{Experimental Test Rig}

Experimental research was performed on a fully instrumented $50 \mathrm{~Hz}, 30 \mathrm{~kW}$, 4-pole WRIM driven by a speed controlled DC motor to achieve the desired load conditions. The WRIM stator windings were supplied from the grid and the rotor windings were short-circuited in the experiments. The WRIM machine stator and rotor currents and voltages were monitored in the tests using three-phase power analysers while the rotor speed was measured by means of a stub shaft mounted $1024 \mathrm{ppr}$ incremental encoder. The test machine frame vibration was measured by installing a Bruel\&Kjær (B\&K) DT4394 piezoelectric accelerometer on the frame at the top of the drive end end-plate. The AE signal was monitored by a B\&K 4961 multi-field microphone installed at various distances and locations from the machine frame and shaft as detailed in sections 3 and 4 . The measured acceleration and acoustic data were synchronously recorded using a B\&K Pulse real-time acquisition and analysis platform and processed using the Pulse's proprietary Fast Fourier transform (FFT) routine to extract the relevant vibration and $\mathrm{AE}$ signal spectra. The FFT analysis was undertaken with a spectral resolution of $\approx 0.15625 \mathrm{~Hz}$ per point for the investigated low frequency bandwidth of interest in this work $(\approx 0-1 \mathrm{kHz})$, as this range is generally of interest in conventional $\mathrm{AC}$ machine fault diagnosis [10]. A simplified schematic diagram of the laboratory test rig is shown in Fig. 1 for illustration purposes.

The test machine stator was rewound to enable experimental emulation of electrical fault. The coil connections of individual 


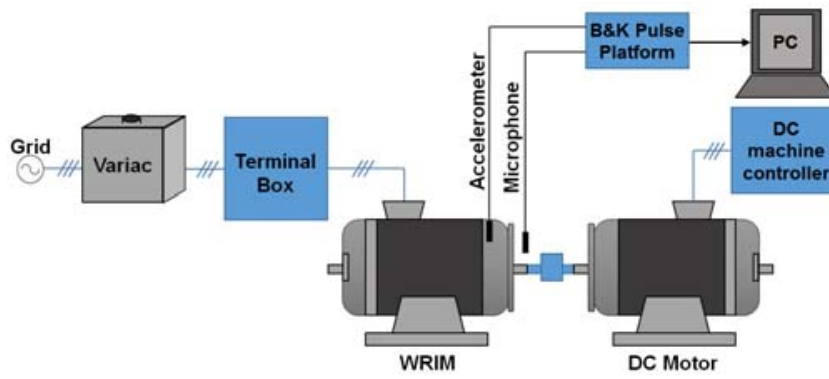

Fig. 1: A simplified schematic diagram of the laboratory test rig

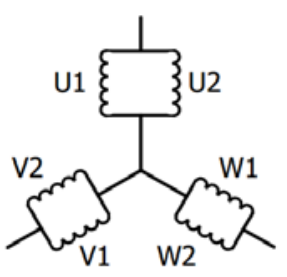

a.Healthy stator and rotor

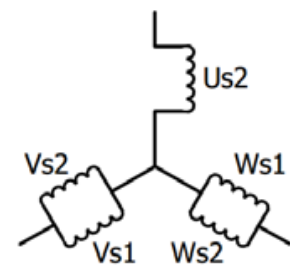

b. Stator open-circuit fault

Fig. 2: Machine winding configurations

stator windings are made accessible via an external terminal box and can be connected to achieve a desired winding configuration [12]. The healthy and faulty configurations examined in this work are shown in Fig. 2. An open-circuit fault was implemented in one parallel branch of a stator phase winding in order to investigate the correlation of its reported spectral effects in the vibration signal $[10,11]$ with any counterpart effects that may be observed in the synchronously measured AE signal spectrum.

\section{Measurement and Results}

The frequency spectrum of the investigated WRIM frame vibration signal was researched in detail in $[10,11]$. These works provide generalised closed form analytical expressions that enable the calculation of possible WRIM electromagnetically induced vibration signal frequencies for healthy and operation with winding fault in arbitrary supply and load conditions. These are summarised in Table 1 for completeness, where $k$ is any positive integer $(k=1,2,3 \ldots), s$

\begin{tabular}{|c|c|c|}
\hline $\begin{array}{c}\text { Operating } \\
\text { Conditions }\end{array}$ & $\begin{array}{c}\text { Eq. } \\
\text { Number }\end{array}$ & $\begin{array}{c}\text { Possible } \\
\text { Vibration/Torque } \\
\text { Signal Frequencies }\end{array}$ \\
\hline $\begin{array}{c}\text { Balanced windings } \\
\text { and supply }\end{array}$ & 1 & $|6 k(1-s)| f_{s}$ \\
\hline $\begin{array}{c}\text { Balanced windings } \\
\text { and unbalance supply }\end{array}$ & 2 & $|2-6 k(1-s)| f_{s}$ \\
\hline $\begin{array}{c}\text { Unbalanced windings } \\
\text { and supply }\end{array}$ & 5 & $|2+6 k(1-s)| f_{s}$ \\
\hline
\end{tabular}

Table 1: General expressions defining the possible vibration signal frequencies is the rotor slip, $p$ is the pole-pair number and $f_{s}$ is the supply fundamental frequency.

It is generally expected that a significant level of correlation would exist between the vibration and AE signal spectral content for a given rotating machine design [13]. Building on the knowledge of the vibration signal spectrum of the investigated machine design in healthy and faulty operating conditions and the general theory presented in Table 1, a series of experiments were undertaken to examine the spectral content of the measured AE signal and correlate it with that of the synchronously obtained vibration spectra. The AE spectral measurements presented in sections 3.1 and 3.2 were obtained with the sensing microphone installed at a radial distance of $\approx 30 \mathrm{~cm}$ from the machine frame, at shaft height and at the frame axial centre length position.

\subsection{Vibration and AE signals spectral content}

The spectral content of the WRIM vibration and AE signals measured in tests for healthy operation and operation with a stator open-circuit fault is examined in this section. The presented data are obtained for a typical test machine operating point in the generating region $(\approx 1590 \mathrm{rpm}, \approx$ fullload operation of the test system) and are presented here for detailed FFT spectrum illustration purposes; the results of a wider study of spectral effects within the nominal operating range of the test system are reported in section 3.2.

The measured healthy and faulty vibration spectra of the test machine content are seen to follow the form reported in [10, 11 ] and contain a number of pronounced spectral components of electromagnetic origin; the frequencies of individual spectral components of significance are identified in Figs. 3-4 (where ' $\mathrm{H}$ ' used to denote components specific of healthy operating conditions and ' $F$ ' denotes those components that arise from winding fault). The frequencies of all the components identified in the graphs can be calculated for the investigated load conditions from the expressions shown in Table 1 and are summarised along with the corresponding equation number and $k$ value in Table 2 .

An examination of the healthy machine vibration spectrum in Fig. 3a reveals the presence of the electromagnetically induced components at frequencies characteristic for balanced machine operation (i.e. H3, H6 and H9) as well as those that arise from the inevitable presence of unbalance in the grid supply (i.e. H1, H2, H4, H5, H7 and H8). The magnitudes of the observed spectral frequencies are seen to vary in the measurements where some are more pronounced than others; this is largely an artefact of the machine design inherent different electromagnetic excitation magnitude at different frequencies as well as the characteristics of the examined systems mechanical frequency response [11]. The H1-H9 components are seen to generally be reflected in the $\mathrm{AE}$ signal as spectral components of identical frequency, as illustrated by the synchronously measured AE spectrum shown in Fig. 3b. For operation with an open-circuit fault, the measured vibration signal spectrum shown in Fig. 4a exhibits the presence of a range of additional, fault induced 


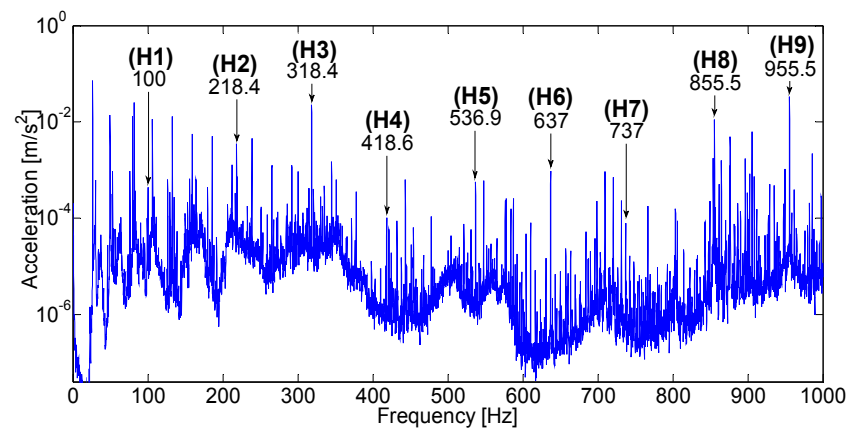

a.Vibration

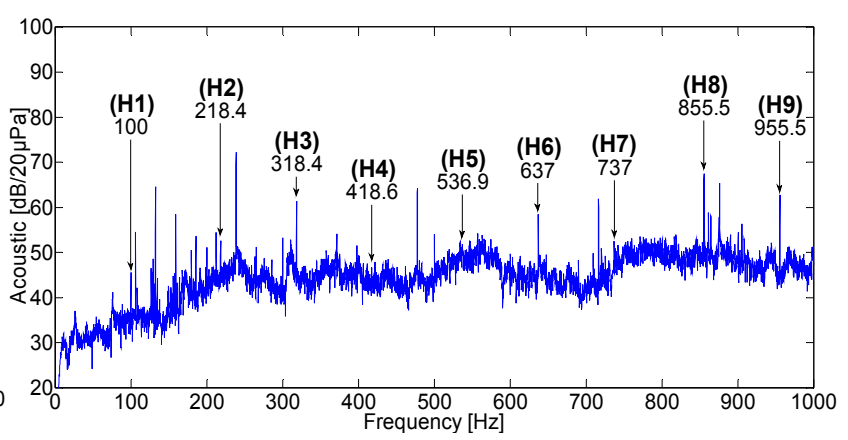

b. $\mathrm{AE}$

Fig. 3: Measured spectra for operation with balanced windings, $\approx 1590 \mathrm{rpm}$

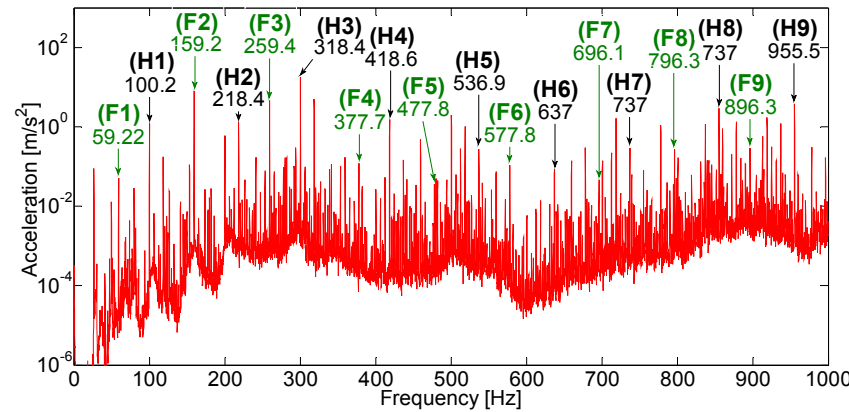

a.Vibration

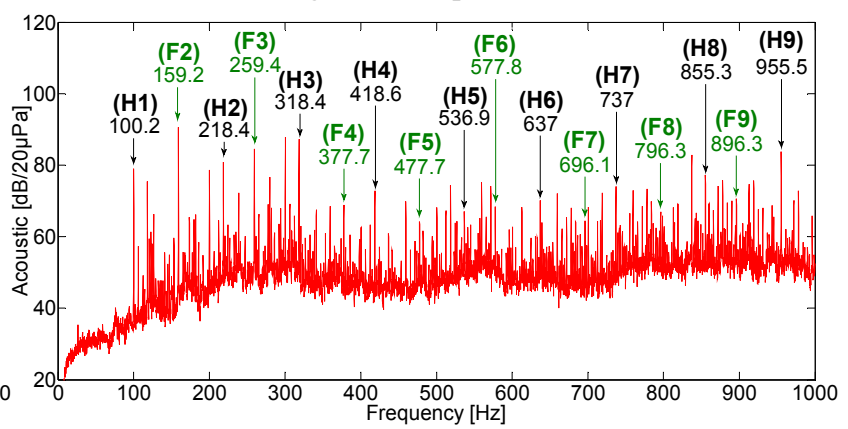

b. $\mathrm{AE}$

Fig. 4: Measured spectra for operation with a stator open-circuit fault, $\approx 1590 \mathrm{rpm}$

\begin{tabular}{|c|c|c|c|c|c|c|c|}
\hline \multicolumn{4}{|c|}{$\begin{array}{c}\text { Healthy Spectrum } \\
\text { Frequencies }\end{array}$} & \multicolumn{4}{c|}{ Electrical Fault Induced } \\
\hline$k$ & Eq. & $\begin{array}{c}\text { Freq. } \\
{[\mathrm{Hz}]}\end{array}$ & Comp. & $k$ & Eq. & $\begin{array}{c}\text { Freq. } \\
{[\mathrm{Hz}]}\end{array}$ & Comp. \\
\hline 0 & $2-3$ & 100 & $\mathrm{H} 1$ & 6 & 5 & 59 & $\mathrm{~F} 1$ \\
\hline 1 & 2 & 218 & $\mathrm{H} 2$ & 6 & 4 & 159 & $\mathrm{~F} 2$ \\
\hline 1 & 1 & 318 & $\mathrm{H} 3$ & 6 & 6 & 259 & $\mathrm{~F} 3$ \\
\hline 1 & 3 & 418 & $\mathrm{H} 4$ & 18 & 5 & 377 & $\mathrm{~F} 4$ \\
\hline 2 & 2 & 536 & $\mathrm{H} 5$ & 18 & 4 & 477 & F5 \\
\hline 2 & 1 & 636 & $\mathrm{H} 6$ & 18 & 6 & 577 & F6 \\
\hline 2 & 3 & 736 & $\mathrm{H} 7$ & 30 & 5 & 695 & F7 \\
\hline 3 & 2 & 854 & $\mathrm{H} 8$ & 30 & 4 & 795 & F8 \\
\hline 3 & 1 & 954 & H9 & 30 & 6 & 895 & F9 \\
\hline
\end{tabular}

Table 2: Calculated frequency values of the vibration and acoustic signal frequencies identified in measurements at $1590 \mathrm{rpm}$

components that can be observed at frequencies F1-F9. A direct comparison with the synchronously measured $\mathrm{AE}$ spectrum of the faulty machine shown in Fig. $4 \mathrm{~b}$ demonstrates that the majority of the fault induced components observed in the vibration spectrum are reflected as counterpart $\mathrm{AE}$ spectral components at identical frequencies (i.e. F2-F9) with the exception of F1 which cannot be recognised in the measured $\mathrm{AE}$ spectrum due to the limitation of the acoustic sensing equipment.

The measured data demonstrate a good agreement between the vibration and the $\mathrm{AE}$ spectra where the electromagnetically induced spectral content of interest is concerned. The minute differences between the calculated and measured frequency values are due to the inherent oscillations in supply frequency and operating speed on the laboratory rig; an ideal $50 \mathrm{~Hz}$ supply and a speed of $1590 \mathrm{rpm}$ were assumed in the calculations in Table 2. It should also be noted that the presented data contain a large number of additional frequency components mostly originating from the mechanical unbalance, mechanical response of the machine frame and supply harmonic effects that are not of direct interest in this research $[6,13]$. While these are not identified in the graphs for the purpose of clarity, the spectral patterns of the inherent mechanical unbalance induced (i.e. integer multiples of fundamental rotational speed $f_{r}: \approx 27 \mathrm{~Hz}, \approx 54 \mathrm{~Hz}, \approx 71 \mathrm{~Hz} \ldots$ for the investigated load point) and supply harmonic effects induced (i.e. integer multiples of $f_{s}$ ) vibration components are seen to remain largely consistent between corresponding datasets in Figs. 3-4. More importantly, it can be seen that the winding fault induced components can for the most part be clearly identified in the $\mathrm{AE}$ spectrum and are directly correlated to their vibration signal origins, i.e. are manifested at identical frequencies of their counterpart components in the vibration signal. This suggests that WRIM winding fault recognition through wide band $\mathrm{AE}$ spectral signature analysis could be feasible on the investigated WRIM design.

\subsection{Load Dependency Study}

The consistency of the manifestation of spectral effects reported in section 3.1 within the nominal operating range of the examined test system is investigated in this section. For this purpose the vibration and $\mathrm{AE}$ spectra measurements were taken for healthy and faulty machine operation in no-load $(\approx 1495 \mathrm{rpm}), \approx 33 \%$ load $(\approx 1530 \mathrm{rpm}), \approx 66 \%$ load $(\approx 1560$ 
rpm $)$ and full-load $(\approx 1590 \mathrm{rpm})$ conditions. The obtained spectra were found to exhibit content patterns that match those observed for full-load operation in section 3.1, but are manifested at different spectral frequencies as is expected from their general definitions in Table 1. The magnitudes of the individual healthy and faulty components of interest defined in Table 2 were extracted from the measured data and presented in a load dependency study form in Fig. 5 for healthy machine operation (i.e. for components H1-H9) and in Fig. 6 for operation with winding fault (i.e. for components F2-F9). The frequencies of the individual examined frequency components were calculated for a given load conditions by utilising the information in Table 2 that maps the specific components' frequency order (i.e. the value of parameter $k$ ) for any given load condition (i.e. the value of rotor slip $s$ ) in a corresponding general form expression in Table 1.

The results of the load study demonstrate that the majority of the observed spectral components of interest exhibit an increase in magnitude with load, as seen in Figs. 5-6. This is

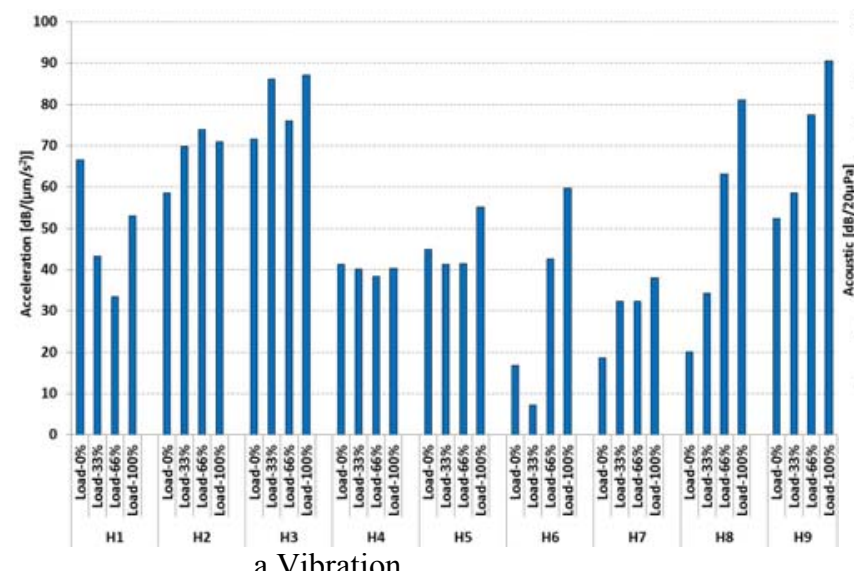

Fig. 5: Influence of load on identified healty spectral components
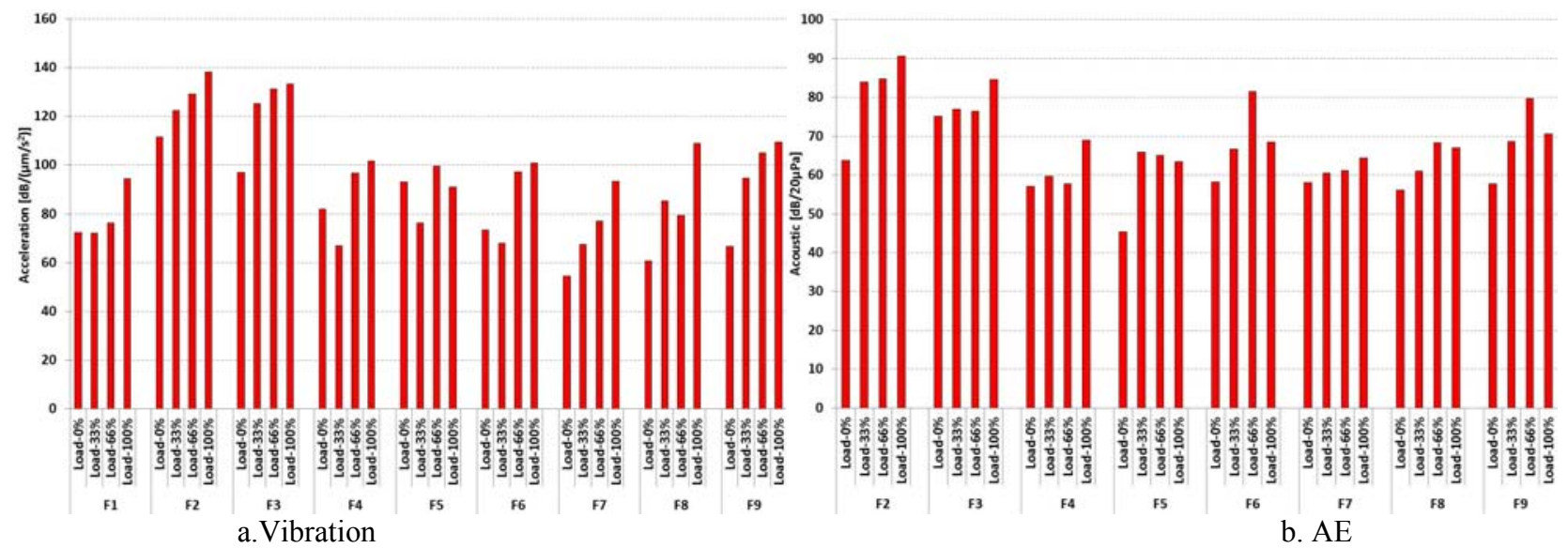

Fig. 6: Influence of load on identified spectral components with the existence of stator open-circuit fault

\section{AE Sensor Positioning Sensitivity Study}

The influence of the AE sensor placement on the recognition of the reported spectral effects in the AE signal is examined in this section. Two separate studies were undertaken to generally an expected behaviour as, in principle, the electromagnetic forces that give rise to the corresponding vibration signal components and the resulting AE spectral components will be greater at higher loads. It should also be noted that this behaviour may be compromised by a number of factors in the system, such as the mechanical response characteristics [11], however these effects are out of the scope of this study. Interestingly, the magnitude variation observed between the individual measured vibration components in Figs. 5a and 6a is not as pronounced in the corresponding $\mathrm{AE}$ measurements in Figs. $5 \mathrm{~b}$ and $6 \mathrm{~b}$. However, the presented results illustrate that the majority of the observed spectral components are consistently exhibited in the $\mathrm{AE}$ and vibrations signals spectra for the nominal operating range and that their monitoring and correlation may provide a useful diagnostic index containing improved diagnostic reliability information on the presence of electrical asymmetry in the investigated WRIM design.

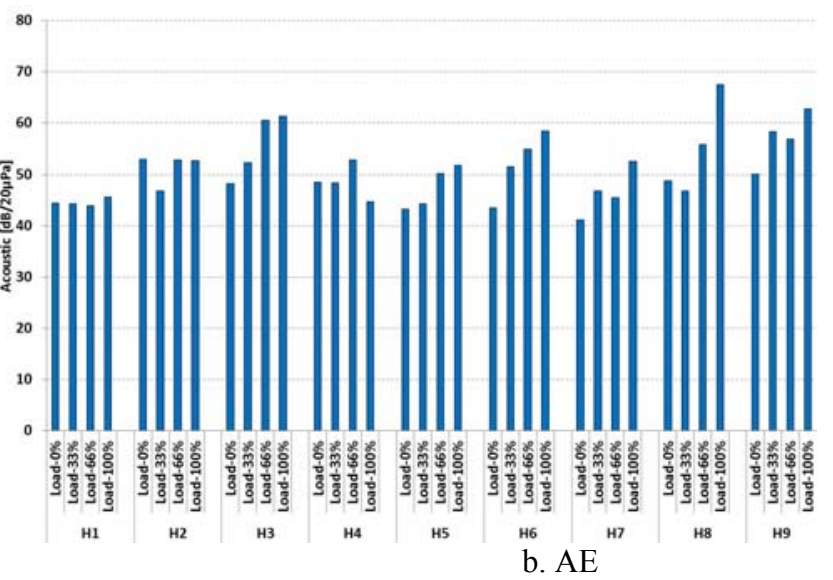

independently assess the effect of the AE sensing separation distance from the machine frame and the AE sensing location in the proximity of the machine frame in practical tests. Measurements were performed for healthy and winding fault operating conditions at $\approx 1590 \mathrm{rpm}$ for simplicity, since the 
AE spectral content of interest for this operating speed is examined in detail for balanced and unbalanced operation in section 3 .

\subsection{AE Sensing Proximity Study}

In order to assess the influence of $\mathrm{AE}$ sensor separation distance from the test machine frame a number of tests were performed in which the radial distance from the sensing microphone to the frame was altered in the following predefined steps: $\approx 1 \mathrm{~cm}, \approx 10 \mathrm{~cm}, \approx 20 \mathrm{~cm}$ and $\approx 30 \mathrm{~cm}$. In all performed tests the AE sensor was installed at shaft height and at the frame axial centre length position. A graphical illustration of the examined AE sensing placement is provided in Fig. 7.

The obtained measurements were processed to extract the magnitudes of the individual healthy (H1-H9) and faulty (F2F9) components of interest. The recorded variation with position of individual compoents is shown for healthy and faulty machine operation in Figs. 8 and 9, respectively. As is generally expected [13] the recorded AE component magnitudes decay with the increase of $\mathrm{AE}$ sensor placement distance from the machine frame. While the recorded compoment magnitudes are the highest when $\mathrm{AE}$ sensor is placed nearest to the motor frame the data in Figs. 8-9 demonstrate that all the considerered $\mathrm{AE}$ sensing positions deliver a reliable recognition of the electromagntically induced AE signal effects for both healthy and faulty operation.

\subsection{Sensor Placement Study}

The influence of the AE sensing location in the proximity of the test machine on the observability of the reported $\mathrm{AE}$ effects was researched in laboratory experiments by undertaking $\mathrm{AE}$ measurements in three different locations. These included the AE sensor placement at the frame axial centre length position, at the machine drive end end-plate and at the machine shaft. For all the performed tests the AE sensor was installed at shaft height and a radial distance of $\approx 30 \mathrm{~cm}$ from the machine. Fig. 10 gives a graphical illustration of the examined AE sensing locations.

The resulting $\mathrm{AE}$ measurements were analysed for magnitudes of individual healthy (H1-H9) and faulty (F2-F9) components of interest. The results are organised to show the

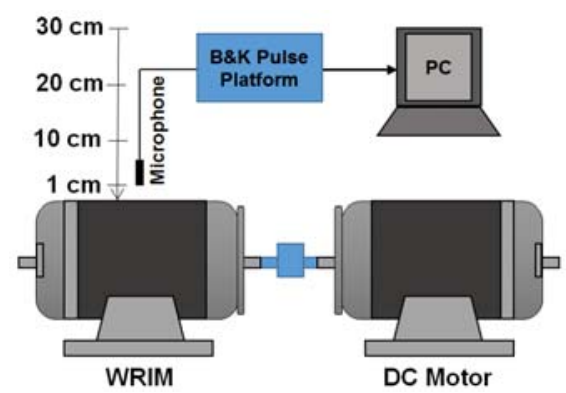

Fig. 7: Examined AE Sensor Placement in the Proximity Study variation of individual components' measured magnitude with the AE sensor location change and are shown in Fig. 11 and 12 for healthy and faulty operating conditions, respectively. The results indicate that, while a moderately low variation in the measured magnitude of individual components can be observed, the electromagnetically induced AE spectral effects of interest are in general relatively uniform with respect to the investigated sensing location. This suggests that the recognition of the discussed electrical fault effects in the $\mathrm{AE}$ signal can be facilitated by all the investigate AE sensing positions.

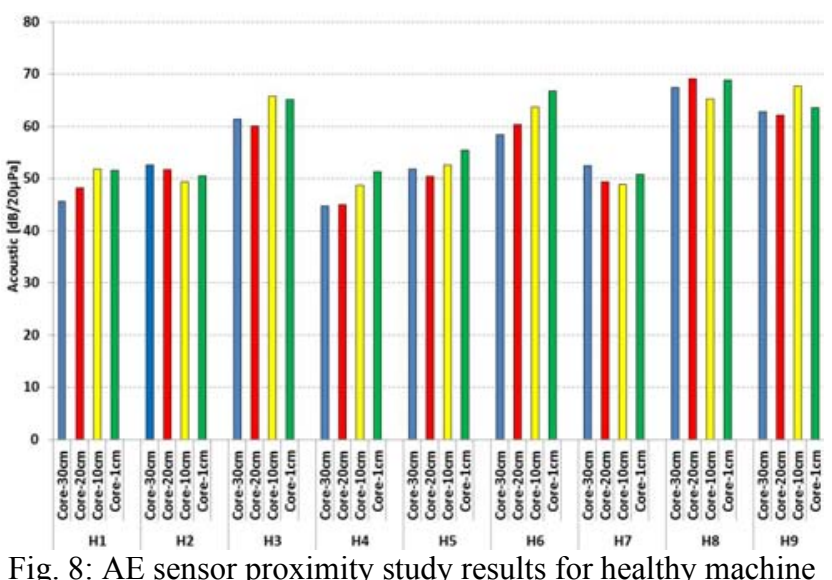

Fig. 8: AE sensor proximity study results for healthy machine operation, $\approx 1590 \mathrm{rpm}$

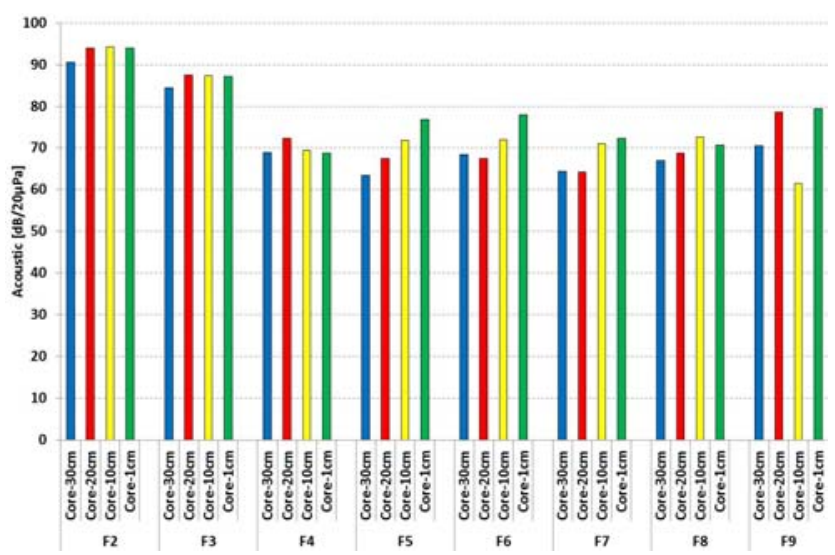

Fig. 9: AE sensor proximity study results for machine operation with winding fault, $\approx 1590 \mathrm{rpm}$

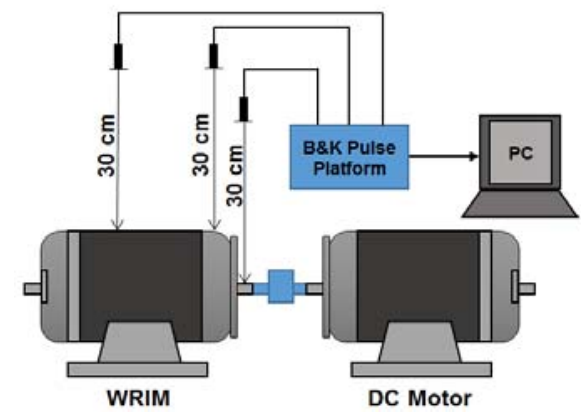

Fig.10: Schematic diagram of the michrophone placement study on the $30 \mathrm{~kW}$ test-rig 


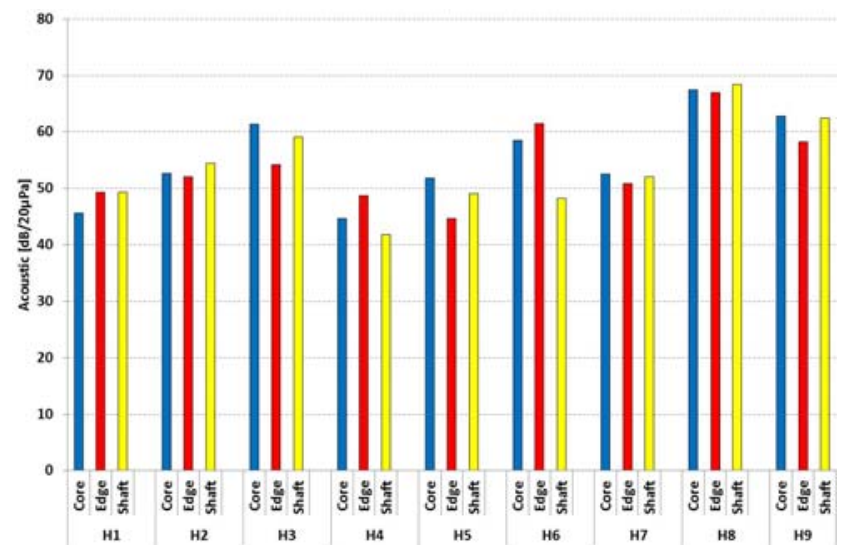

Fig.11: AE sensor placement study results for healthy machine operation, $\approx 1590 \mathrm{rpm}$

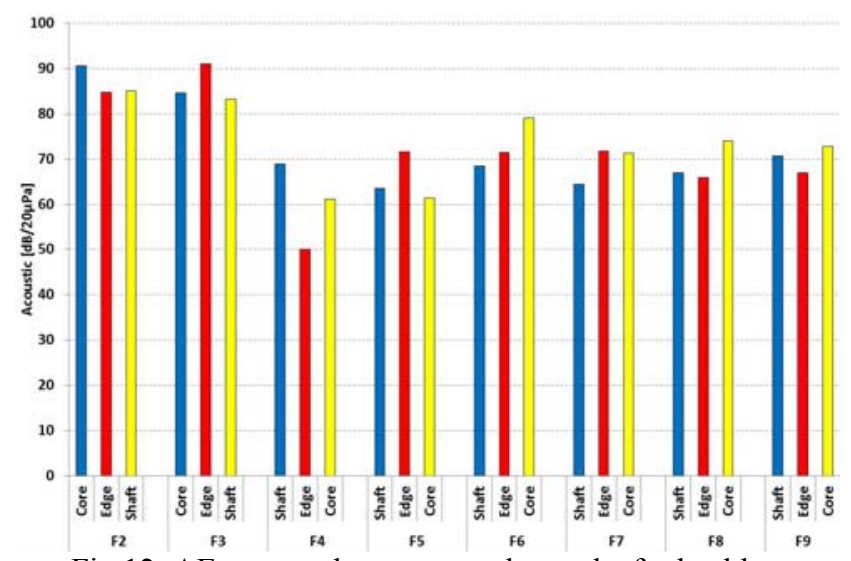

Fig.12: AE sensor placement study results for healthy machine operation, $\approx 1590 \mathrm{rpm}$

\section{Conclusions}

This paper reports a detailed experimental study of vibroacoustic emissions of an industrial WRIM design operating in healthy conditions and with a stator winding open-circuit fault. The findings provide a deeper insight into the possible spectral nature of WRIM acoustic emissions. The reported experimental results show a direct cross-correlation between WRIM vibration and AE spectral content that provides a clearer understanding of possible spectral signature of stator winding fault in WRIMs and could facilitate their improved recognition. The paper also provides a study of acoustic sensor placement in order to better understand the implications of AE sensing distance and location on reliable recognition of the observed spectral trends.

\section{References}

[1] Hassan, GL Garrad. "A guide to UK offshore wind operations and maintenance." Scottish Enterprise and the Crown Estate (2013).

[2] UpWind, "Design limits and solutions for very large wind turbines", Editor March 2011, Risø National Laboratory - DTU.
[3] Alewine, K., et al., "A review of electrical winding failures in wind turbine generators." Electrical Insulation Conference (EIC), 2011. IEEE, 2011.

[4] Alewine, K., et al., "Wind turbine generator failure modes analysis and occurrence." Wind Power 2010 Conference, Dallas. 2010.

[5] Crabtree, C.J., et al., "Survey of commercially available condition monitoring systems for wind turbines." Durham University: Durham, UK, 2010.

[6] Y. Amirat et al. "A brief status on condition monitoring and fault diagnosis in wind energy conversion systems," Renewable and Sustainable Energy Reviews, Volume 13, Issue 9, December 2009.

[7] Crabtree, C.J.; Djurovic, S.; Tavner, P.J.; Smith, A.C., "Condition monitoring of a wind turbine DFIG by current or power analysis," in Power Electronics, Machines and Drives (PEMD 2010), 5th IET International Conference on , vol., no., pp.1-6, 19-21 April 2010

[8] Ackermann, T.,"Wind Power in Power Systems," Hoboken, NJ, USA: Wiley 2005.

[9] Djurovic, S., et al., "Condition monitoring of wind turbine induction generators with rotor electrical asymmetry." IET Renewable Power Generation 6.4 (2012): 207-216.

[10] Djurovic, S.; Vilchis-Rodriguez, D.S.; Smith, A.C., "Vibration monitoring for wound rotor induction machine winding fault detection," in Electrical Machines (ICEM), 2012 XXth International Conference on , vol., no., pp.1906-1912, 2-5 Sept. 2012

[11] Djurovic, S., Vilchis-Rodriguez, D.S., Smith, A.C., "Investigation of wound rotor induction machine vibration signal under stator electrical fault conditions," The IET Journal of Engineering, pp.. 1-11, May 2014

[12] Williamson, S., Djurovic, S., "Origins of stator current spectra in DFIGs with winding faults and excitation asymmetries," in Electric Machines and Drives Conference, 2009., vol., no., pp.563-570, 3-6 May 2009 doi: 10.1109/IEMDC.2009.5075262

[13] Cempel, C., "Vibroacoustic Condition Monitoring (Ellis Horwood Series in Mechanical Engineering)", Ellis Harwood Ltd. 1993. 